\title{
Author Correction: The genomics of childhood eating behaviours
}

Moritz Herle (D), Mohamed Abdulkadir, Christopher Hübel DD, Diana Santos Ferreira, Rachel Bryant-Waugh, Ruth J. F. Loos (iD, Cynthia M. Bulik (iD, Bianca De Stavola and Nadia Micali (iD

Correction to: Nature Human Behaviour https://doi.org/10.1038/s41562-020-01019-y, published online 11 January 2021.

In the version of this article initially published, middle initials were omitted for author Ruth J. F. Loos. The error has been corrected in the PDF and HTML versions of this article.

Published online: 16 February 2021

https://doi.org/10.1038/s41562-021-01072-1

(c) The Author(s), under exclusive licence to Springer Nature Limited 2021 